\title{
Estimating Friction Factors in a Fouled Annulus
}

\author{
L. F. MELO and J. D. PINHEIRO
}

Centro de Quimica Pura e Aplicada, University of Minho, Braga, Portugal

\begin{abstract}
Fouling of heat transfer surfaces modifies the associated conductive thermal resistance and convective heat transfer coefficient. Often, the latter varies as a result of changes in the roughness of the deposition surface. If fouling is being studied in an annular heat exchanger, deposits may form on both surfaces of the annular cross section, and an estimation of the friction factors of each fouled surface is needed. In order to evaluate these factors a simple method can be used as described in this paper, based on pressure drop measurements and current equations. Experimental results are reported and appear to support the method.
\end{abstract}

L'encrassement des surfaces de transfert de chaleur modifie leur résistance thermique conductive et leur coefficient de transfert de chaleur par convection. Celui-ci change, souvent, comme résultat de variations de la rugosité de la surface causées par des dépôts. Dans un échangeur de section annulaire, les dépôts peuvent se former sur les deux surfaces de l'espace annulaire. Il est donc nécessaire de calculer les coefficients de frottement de chacune de ces surfaces, ce qui peut être accompli en appliquant la méthode décrite ici, basée sur des équations simples et des mesures de la perte de charge. Les résultats expérimentaux semblent confirmer la validité de cette méthode.

$\mathrm{S}_{\mathrm{in}}^{\mathrm{m}}$ mall-scale annular heat exchangers are commonly used in experimental fouling studies. During the fouling tests the build-up of deposits causes changes in the pressure drop and, particularly, in the friction factors of both the inner and the outer tubes. Usually, the inner wall of the annular section is the fouled surface of greater interest, and the calculation of its friction factor is important in evaluating the actual convective heat transfer coefficient and the thermal resistance of the deposited materials (Bott and Walker, 1971; Epstein, 1978).

A simple method for estimating the friction factors associated with the inner and outer surfaces of the annulus is described below, based on pressure drop measurements and current equations. It is assumed that the deposit thickness is much smaller than the annulus width, so that blockage effects may be neglected. This is a reasonable assumption in most fouling rigs, as Epstein (1978) pointed out; it was again confirmed by the results of the fouling test reported below.

The total force exerted by the fluid on the solid walls is (Bird et al., 1960):

$$
F_{1}+F_{2}=\pi \Delta P\left(r_{2}^{2}-r_{1}^{2}\right)
$$

The shear stresses and the friction factors on each wall are given by:

$$
\begin{aligned}
& \tau_{i}=F_{i} / 2 \pi r_{i} L \\
& f_{i}=2 \tau_{i} / \rho u^{2} .
\end{aligned}
$$

( $i=1$ or 2 , depending on the surface being considered). Thus, from Equations (1) to (3) one gets:

$$
f_{1} r_{1}+f_{2} r_{2}=\Delta P\left(r_{2}^{2}-r_{1}^{2}\right) / L \rho u^{2}
$$

At the beginning of the fouling test the inner and outer surfaces are clean and smooth, and the ratio of the corresponding friction factors is (Walker and Rothfus, 1959):

$$
\left(f_{1}\right)_{0} /\left(f_{2}\right)_{0}=\left(\tau_{1}\right)_{0} /\left(\tau_{2}\right)_{0}=r_{2}\left(r_{m}^{2}-r_{1}^{2}\right) /\left[\left(r_{2}^{2}-r_{m}^{2}\right) r_{1}\right]
$$

In laminar flow, the radius of maximum fluid velocity, $r_{m}$, can be predicted theoretically (Bird et al., 1960):

$$
r_{m}^{2}=\left(r_{2}^{2}-r_{1}^{2}\right) / 2 \ln \left(r_{2} / r_{1}\right)
$$

According to the experimental work of Rothfus, Walker and Whan (1958) and of Walker and Rothfus (1959), Equation (6) appears to hold also for turbulent flow; their results show that the deviation is only $2.5 \%$ at $\mathrm{Re}=3000$ and decreases with increasing Re. Hence, it is assumed that $r_{m}$ has similar values for laminar and turbulent regimes. This assumption is further confirmed by Brighton and Jones (1964) for $r_{1} / r_{2}>0.5$.

In Equations (4) and (5) the unknowns are: $f_{1}, f_{2}$ and $\Delta P$. Therefore, if the initial value of $\Delta P$ is measured and entered into Equation (4), the initial values of the friction factors of both surfaces are determined.

When the annulus is fouled, Equation (6) cannot be safely used because of the unpredictable effects of the rough deposit on the velocity profile, particularly on $r_{m}$. However, values of $f_{1}$ and $f_{2}$ for the fouled annulus can be calculated if the fouled inner tube is replaced by a clean, but otherwise similar, tube, and the pressure drop measured without cleaning the outer tube. With this procedure, two different $\Delta P$ values, related to the fouled annulus condition namely, $(\Delta P)_{f}$ and $\left(\Delta P_{2}\right)_{f}-$ are available and can be used in Equations ( 7 ) and (8), these being obtained from Equation (4) for the following two cases: Inner tube clean, outer tube fouled:

$$
\left(f_{1}\right)_{0} r_{1}+\left(f_{2}\right)_{f} r_{2}=\left(\Delta P_{2}\right)_{f}\left(r_{2}^{2}-r_{1}^{2}\right) / L \rho u^{2} \ldots \ldots \ldots
$$

Both tubes fouled:

$$
\left(f_{1}\right)_{f} r_{1}+\left(f_{2}\right)_{f} r_{2}=(\Delta P)_{f}\left(r_{2}^{2}-r_{1}^{2}\right) / L \rho u^{2}
$$

Solving for $\left(f_{1}\right)_{f}$ and $\left(f_{2}\right)_{f}$, these friction factors of each fouled surface are obtained.

Alternatively - instead of replacing the fouled inner tube by a clean tube - one can replace the outer tube and use the following equation instead of Equation (7):

$$
\left(f_{1}\right)_{f} r_{1}+\left(f_{2}\right)_{0} r_{2}=\left(\Delta P_{1}\right)_{f}\left(r_{2}^{2}-r_{1}^{2}\right) / L \rho u^{2}
$$


TABLE 1

Friction Factors in an Annular Heat Exchanger Subjected to Particulate Fouling

\begin{tabular}{|c|c|c|c|c|c|c|}
\hline \multicolumn{7}{|c|}{ Friction factors $\left(\times 10^{3}\right)$} \\
\hline \multicolumn{2}{|c|}{ Overall, $f$} & \multicolumn{2}{|c|}{ Outer tube, $f_{2}$} & \multicolumn{3}{|c|}{ Inner tube, $f_{1}$} \\
\hline Clean & Fouled & Clean & Fouled & Clean & Fol & led \\
\hline \multirow[t]{2}{*}{7.8} & 9.1 & 7.4 & 8.3 & 8.5 & 10.4 & 10.0 \\
\hline & & & & & $\begin{array}{c}\text { Measuring } \\
\left(\Delta P_{2}\right)_{f}\end{array}$ & $\begin{array}{c}\text { Measuring } \\
\left(\Delta P_{1}\right)_{f}\end{array}$ \\
\hline
\end{tabular}

Solving now Equations (8) and (9) for $\left(f_{1}\right)_{j}$ and $\left(f_{2}\right)_{j}$, one should obtain the same values as before.

The method described was used by Melo and Pinheiro (1984) to estimate friction factors in a fouled annular heat exchanger with a radius ratio $r_{1} / r_{2}=0.7$ and an equivalent diameter of $11 \mathrm{~mm}$, in which kaolin deposited from a kaolin-water suspension flowing at a Reynolds number of 7000. The results obtained are shown in Table 1 from which it is possible to note that the relative increase in the friction factor of the inner tube is greater than the increase in the overall friction factor. The latter is directly calculated from the pressure drop measurements, through:

$$
f=\Delta P D_{e} / 2 L \rho u^{2}
$$

where $D_{e}=2\left(r_{2}-r_{1}\right)$. A simple dependence of $f$ on $f_{1}, f_{2}$, $r_{1}$ and $r_{2}$ can be obtained from Equations (4) and (10):

$$
f=\left(f_{1} \cdot r_{1}+f_{2} \cdot r_{2}\right) /\left(r_{1}+r_{2}\right)
$$

which is valid for any annulus (clean or fouled).

The difference between the two values of $\left(f_{1}\right)_{f}$ presented in Table 1 will be mainly due to a slight difference $(2.1 \%)$ in the roughness of the two inner tubes used in the experiment (which can be assessed before the fouling test). Note that the overall friction factor for the fouled annulus calculated with Equation (11) using $\left(f_{1}\right)_{f}=10.0$ is 9.0, deviating about $1 \%$ from the measured $f$.

The fact that the thickness of the kaolin deposit $(70 \mathrm{mi}-$ crons on the average) is much smaller than the annulus diameter minimizes the possible blockage effects. In the present case the increase in fluid velocity due to blockage is only $2 \%$, leading to a minor raise in the convective heat transfer coefficient $(1.6 \%$, obtained from the usual heat transfer correlations), while the change in that coefficient due to roughness is about $18 \%$, as given by the Norris' correlation (Walker and Bott, 1973).

In cases where blockage effects are of some practical importance, although not prevailing, the method can still be used if an estimate of the deposit's thickness is available, enabling the correction of the fluid velocity in Equations (7) and (8). It should also be stressed that the effects of fluid velocity and of roughness in the convective heat transfer coefficient are qualitatively the same, because they both tend to increase turbulence.

\section{Acknowledgement}

The financial support of Junta Nacional de Investigaçăo Cientifica e Tecnológica (JNICI), Portugal, is gratefully acknowledged.

\section{Nomenclature}

$D_{e} \quad=$ equivalent diameter of the annulus, $\mathrm{m}$

$F_{1}, F_{2}=$ fluid forces acting on the inner and outer surfaces of the annular section, $\mathbf{N}$

$f=$ overall friction factor

$f_{1}, f_{2}=$ friction factors of the inner and outer tubes

$L \quad=$ length of annulus used in pressure drop measurements, m

$\Delta P=$ pressure drop, $\mathrm{N} / \mathrm{m}^{2}$

$\left(\Delta P_{1}\right)_{f}=$ pressure drop with the fouled inner tube and a clean outer tube, $\mathrm{N} / \mathrm{m}^{2}$

$\left(\Delta P_{2}\right)_{f}=$ pressure drop with a clean inner tube and the fouled outer tube, $\mathrm{N} / \mathrm{m}^{2}$

$r_{1}, r_{2}=$ radii of the inner and the outer tubes, respectively, $\mathrm{m}$

$r_{m} \quad=$ radius of maximum fluid velocity, $\mathrm{m}$

$u \quad=$ mean fluid velocity, $\mathrm{m} / \mathrm{s}$

\section{Greek letters}

$\rho=$ fluid density, $\mathrm{kg} / \mathrm{m}^{3}$

$\tau_{1}, \tau_{2}=$ shear stresses on the inner and outer walls of the annular section, $\mathrm{N} / \mathrm{m}^{2}$

\section{Subscripts}

$1=$ inner wall of the annular section

$2=$ outer wall of the annular section

$0 \quad=$ clean surface

$f \quad=$ fouled surface

\section{References}

Bird, R. B., E. B. Stewart and E. N. Lightfoot, "Transport Phenomena", Chap. 2, John Wiley and Sons, New York (1960).

Bott, T. R. and R. A. Walker, "Fouling in Heat Transfer Equipment", The Chem. Engr. (London), 391-395 (1971)

Brighton, J. A. and J. B. Jones, "Fully Developed Turbulent Flow in Annuli", J. Basic Eng., 835-845 (1964).

Epstein, N., "Fouling of Heat Exchangers", in "Heat Transfer 1978 - Proceed. 6th Int. Heat Transfer Conf.", 6, 235-253, Hemisphere Publ. Corp. (1979).

Melo, L. F. and J. D. Pinheiro, "Hydrodynamic Effects in Particulate Fouling", I. Chem. E. Symp. Ser. No. 86, 1, 381-390 (1984).

Rothfus, R. R., J. E. Walker and G. A. Whan, "Correlation of Local Velocities in Tubes, Annuli and Parallel Plates", AIChE J. 4(2), 240-245 (1958).

Walker, R. A. and T. R. Bott, "Effect of Roughness on Heat Transfer in Exchanger Tubes", The Chem. Engr. (London), $151-156$ (1973).

Walker, J. E. and R. R. Rothfus, "Transitional Velocity Patterns in a Smooth Concentric Annulus", AIChE J. 5(1), 51-54 (1959).

Manuscript received October 30, 1984; revised manuscript received February 5, 1985; accepted for publication February 25, 1985 . 